\title{
Colnstio \\ Tomada de decisão do gestor escolar das escolas públicas de ensino médio no Distrito Federal e a interface com o letramento informacional
}

\author{
Patrícia Resende Pereira \\ Mestre; Universidade de Brasília, Brasília, DF, Brasil \\ patriciaresendeeduc@hotmail.com \\ Kelley Cristine Gonçalves Dias Gasque \\ Doutora; Universidade de Brasília, Brasília, DF, Brasil \\ kelleycristinegasque@hotmail.com
}

\begin{abstract}
Resumo: O estudo analisou o comportamento de busca e uso da informação para a tomada de decisão do gestor escolar, em relação aos padrões de letramento informacional nas escolas de ensino médio do Distrito Federal da rede pública de ensino. A pesquisa é de natureza quali-quantitativa, com uso de documentos oficiais do sistema educacional do Distrito Federal, questionário e entrevista semiestruturada. Os resultados mostram que o principal acesso à informação é realizado pela internet e que o volume de dados, aliado à falta de tempo para obtenção de informações, dificulta a tomada de decisão. Para tomar decisões, os gestores consultam informações disponíveis na escola, além do projeto político pedagógico. Verificam a origem da informação recebida e os resultados alcançados pela escola nas avaliações externas do governo. Por fim, os dados coletados pelos gestores educacionais, em relação aos padrões do letramento informacional, mostram o desenvolvimento de poucas habilidades e a necessidade de formação sistemática e adequada para aprender a lidar com a informação.
\end{abstract}

Palavras-chave: Letramento Informacional. Gestão Escolar. Tomada de decisão. Ensino médio.

\section{Introdução}

O presente artigo, decorrente de pesquisa de mestrado em ciência da informação, analisou os procedimentos de busca e uso da informação para tomada de decisão do gestor escolar do ensino médio da rede pública do Distrito Federal (DF), e a interface com os padrões de letramento informacional. Para tanto, por meio de pesquisa quali-quantitativa, buscou-se identificar o perfil demográfico do gestor das escolas de ensino médio do Distrito Federal; identificar as categorias de tomada de decisão; comparar os procedimentos de 
Tomada de decisão do gestor escolar das escolas públicas de ensino médio no Distrito Federal e a interface como letramento informacional Patrícia Resende Pereira e Kelley Cristine Gonçalves Dias Gasque

busca e uso da informação para tomada de decisão, considerando os padrões de letramento informacional; bem como investigar a relação entre o processo de tomada de decisão e a interface com os padrões de letramento informacional.

A pesquisa fundamenta-se na suposição de que a informação torna-se capital valioso e imprescindível para a sobrevivência na era da globalização. Destaca-se que a socialização dos conhecimentos e o desenvolvimento de habilidades individuais neste contexto ocupam espaço cada vez mais significativo para as organizações (MORESI, 2000). Além disso, corrobora a pesquisa de Khanna, Jones e Boivie (2014) sobre o capital humano dos diretores como fonte de vantagem competitiva, - isto é, a experiência e educação anteriores. Porém, tal benefício depende da carga de processamento de informações que lhes é imposta nas tarefas de gestão.

Assim, esta pesquisa parte de uma questão de ordem prática, em que o excesso de informações e a sobrecarga de trabalho do gestor educacional impactam a qualidade do ensino. Com efeito, o gestor é o principal responsável pela instituição de ensino e espera-se dele visão de conjunto, espírito de liderança e capacidade para articular e integrar os setores, alcançando melhores resultados para a instituição (LÜCK, 2008).

Considerando os objetivos do Letramento Informacional - LI, os gestores devem desenvolver a capacidade de liderança e atuar no sentido de facilitar o acesso à informação, identificar e manusear fontes de informação de forma efetiva e eficaz (GASQUE, 2010). Outro propósito dos gestores é otimizar o uso dos recursos de informação e de conhecimento como suporte ao processo de decisão e definir estratégias de ação necessárias às atividades escolares, tendo em vista o posicionamento estratégico dentro da instituição de ensino.

\section{Referencial teórico}

Este tópico apresenta os principais aportes teóricos que norteiam esta investigação, com vistas a alcançar os objetivos propostos para o estudo. De acordo com Gasque (2008), o referencial teórico estabelece a base conceitual por meio da qual o problema será estudado, além de direcionar e orientar a interpretação do assunto pesquisado. 
Tomada de decisão do gestor escolar das escolas públicas de ensino médio no Distrito Federal e a interface como letramento informacional Patrícia Resende Pereira e Kelley Cristine Gonçalves Dias Gasque

Para a revisão de literatura, realizou-se consulta sobre o tema nas seguintes bases de dados: Arquivologia, Biblioteconomia, Ciência da Informação, Documentação e Museologia (ABCDM), Base de Dados em Ciência da Informação (BRAPCI), Scientific Electronic Library Online (Scielo), Biblioteca Digital de Teses e Dissertações (BDTD/IBICT), Networked Digital Library of Theses and Dissertations (NDLTD), Proquest, Online Computer Library Center, Inc. (OCLC), Library Information Science \& Technology Abstracts (LISTA), ERIC, Repositório $\mathrm{UnB}^{1}$ e Google Acadêmico. Os descritores utilizados foram "letramento informacional", "gestão escolar" e "processo de tomada de decisão" e a busca foi realizada em língua portuguesa, língua inglesa e língua espanhola.

Foram encontrados estudos que relacionam a contribuição da information literacy para os gestores de empresas, por exemplo, Ottonicar (2016), Santos (2014), Yafushi (2015), bem como a importância da atuação dos gestores escolares para a implementação do LI no ensino superior ou para implementação em bibliotecas escolares, como se verifica nas investigações de Alves (2016), Blakeney (2014), Botha (2013), Manabe e Kaimen (2013). Todavia, verificou-se uma lacuna em relação à contribuição do letramento informacional no processo de gestão escolar no Brasil. Localizou-se apenas um estudo, de Almeida (2015), que trata do uso da informação educacional na perspectiva de gestores de escolas de anos iniciais. Essa constatação reiterou o interesse em prosseguir com a investigação sobre o tema, na perspectiva de contribuir para a melhoria do processo de gestão nas escolas.

A partir da revisão de literatura, adotaram-se os seguintes conceitos:

a) de letramento informacional, baseado nos estudos de Catts e Lau (2009) e Gasque (2012), que definem o LI como o processo de desenvolvimento de competências que permitem localizar, selecionar, acessar, organizar, usar a informação para gerar conhecimento, tomar decisões e resolver problemas. O LI possibilita o desenvolvimento da consciência crítica e estimula a participação ativa na sociedade, na criação de projetos capazes de atuar sobre a realidade. Assim, entende que a proposta está em consonância com o trabalho do gestor, cuja atuação relaciona-se com 
Tomada de decisão do gestor escolar das escolas públicas de ensino médio no Distrito Federal e a interface como letramento informacional

Patrícia Resende Pereira e Kelley Cristine Gonçalves Dias Gasque

o domínio das habilidades em informação para mobilizar e liderar a equipe escolar;

b) da gestão participativa, modelo de gestão que, de acordo com Lück (2008) e Gadotti (2014), implica o engajamento dos colaboradores, propicia a comunicação, estreita laços de confiança e favorece o alcance dos objetivos. Além disso, contempla o ambiente das escolas públicas, estruturadas no modelo de gestão democrática, como foco da pesquisa. Considera-se, ainda, que a gestão participativa favorece fatores essenciais para a qualidade do ensino, como: o comprometimento político do gestor; a busca por alianças e parcerias; a valorização dos profissionais da educação; a gestão democrática; o fortalecimento e a modernização da gestão escolar; e a racionalização e a produtividade do sistema educacional (XAVIER,1996);

c) do modelo proposto por Choo e Rocha (2003) como referencial na análise do processo de gestão e os quatro modelos de tomada de decisão, visto que "o conhecimento organizacional emerge quando os três processos de uso da informação - criação de significado, construção do conhecimento e tomada de decisões - integram-se num ciclo contínuo de interpretação, aprendizado e ação" (CHOO; ROCHA, 2003, p. 411). Considera-se, ainda, a proposta de processo de tomada de decisão de Kahneman (2012), que aborda o pensamento e o comportamento humano sob a perspectiva científica e analisa o processo de pensar, decidir e julgar, indicando erros e desvios comuns no processamento. Nesse estudo, ressalta-se que o processo de tomada de decisão no âmbito escolar está delimitado a duas categorias: administrativa e pedagógica, referenciado pelo regimento escolar da Secretaria de Estado de Educação do Distrito Federal, em vigor desde 2015.

Pelo desenho da pesquisa, apresentado na Figura 1, pode-se observar que os conceitos interagem entre si em um fluxo dinâmico e circular. 


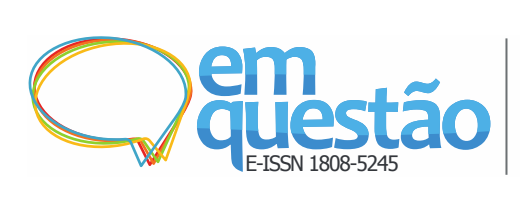

Tomada de decisão do gestor escolar das escolas públicas de ensino médio no Distrito Federal e a interface como letramento informacional Patrícia Resende Pereira e Kelley Cristine Gonçalves Dias Gasque

Figura 1 - Desenho da pesquisa

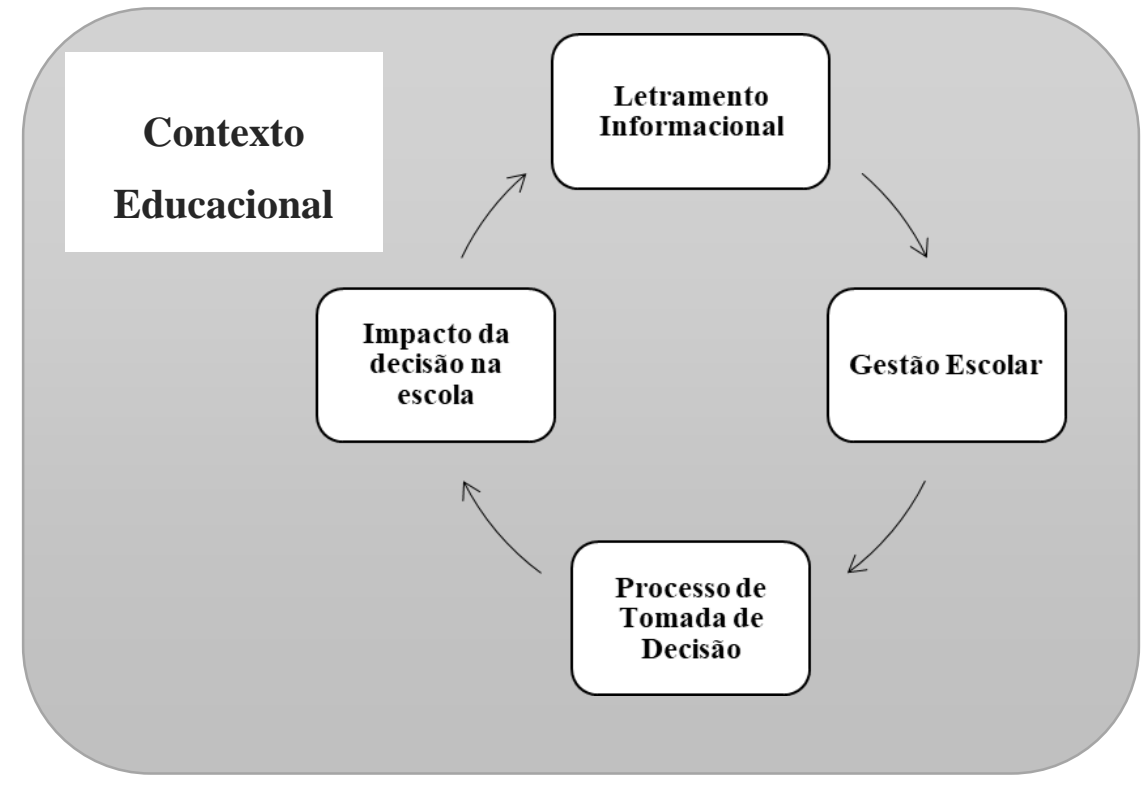

Fonte: Elaborado pelas autoras.

Neste contexto, o letramento informacional tem o potencial de melhorar o trabalho da gestão escolar, quando cria condições para o desenvolvimento da consciência crítica. Possibilita visão reflexiva sobre o trabalho desenvolvido e vislumbra perspectivas educacionais alinhadas com os objetivos da escola, que proporciona diretrizes de ação e facilita o processo de tomada de decisão. Isso, por sua vez, causa impacto direto no cotidiano escolar. O processo deve estar alinhado com a missão educacional, bem como ações e projetos capazes de melhorar o desenvolvimento do contexto educacional.

\section{Metodologia da pesquisa}

A natureza da pesquisa é quanti-qualitativa, pois, conforme descrito por Creswell (2010), conduziu-se a investigação com a coleta de diversos tipos de dados por proporcionar melhor entendimento do problema. Realizou-se estudo de caso com os gestores de 89 escolas públicas do Distrito Federal. O estudo de caso é um tipo comumente empregado para se investigar profundamente determinado fenômeno social. Envolve grande complexidade e necessita do trabalho em campo, considerando a perspectiva dos atores envolvidos e o olhar sobre o fenômeno a ser investigado (YIN, 2005). 
Tomada de decisão do gestor escolar das escolas públicas de ensino médio no Distrito Federal e a interface como letramento informacional Patrícia Resende Pereira e Kelley Cristine Gonçalves Dias Gasque

Os instrumentos de coleta de dados utilizados foram documentos da escola (Projeto Político-Pedagógico, Regimento Interno e outros), questionários aplicados nas 89 unidades escolares em estudo, bem como a realização de seis entrevistas semiestruturadas, que visaram a coleta de pontos de vista e informações mais detalhadas dos participantes.

A amostragem foi composta por gestores escolares de escolas públicas de ensino médio do DF, considerando a variabilidade das características das unidades escolares em relação à localização, organização e ao público alvo dessas escolas, que também se apresentam distintos uns dos outros.

A presente pesquisa foi desenvolvida considerando os seguintes objetivos específicos:

a) a identificação do perfil sociodemográfico do gestor escolar ocorreu por meio da aplicação de questionário com 13 questões, respondido por 21 gestores, no período de 25/09/2017 a 24/11/2017. A caracterização da amostra considerou a viabilidade de análise dos dados coletados e, ainda, a possibilidade de acesso à internet durante o período de realização da pesquisa, uma vez que o questionário foi disponibilizado em plataforma on-line. Além do questionário, extraíram-se informações de pesquisa documental realizada no âmbito da Secretaria de Estado de Educação do Distrito Federal (SEEDF);

b) a identificação das categorias de tomada de decisão e os procedimentos de busca e uso da informação foram investigados por meio de entrevistas realizadas entre 25/10/2017 e 08/11/2017, em seis unidades de ensino (UE): três UE localizadas em regiões com bom desempenho nas avaliações externas, como Exame Nacional do Ensino Médio (ENEM) e Sistema de Avaliação da Educação Básica (SAEB), e outras três que precisam avançar para alcançar as metas previstas pelo Ideb;

c) a identificação das categorias de tomada de decisão e os procedimentos de busca e uso da informação foram realizados mediante elaboração de esquema gráfico do fluxo de ações e/ou das principais atividades para tomada de decisão, a partir dos dados coletados pelos questionário e entrevistas semiestruturadas; 
Tomada de decisão do gestor escolar das escolas públicas de ensino médio no Distrito Federal e a interface como letramento informacional

Patrícia Resende Pereira e Kelley Cristine Gonçalves Dias Gasque

d) a investigação da relação entre o processo de tomada de decisão e os padrões de competência em letramento informacional foi realizada mediante comparação entre os padrões de LI e as respostas dos entrevistados, que incluíram dados da experiência pessoal, recursos e procedimentos adotados na busca e uso da informação, assim como as práticas utilizadas no cotidiano.

As limitações do presente estudo relacionam-se, principalmente, à abrangência e à representatividade da amostra. De acordo com Gasque (2003), apesar de os estudos de caso apresentarem limitações quanto a possíveis generalizações, podem revelar tendências e agregar valor ao corpo de conhecimento da Ciência da Informação e Educação.

\section{Resultados}

Os resultados mostram que o quadro atual de gestores de escolas de ensino médio apresenta perfil equilibrado quanto ao gênero dos profissionais, com ligeira predominância do sexo feminino. A faixa etária está concentrada entre 41 e 50 anos de idade, que coincide com o ápice de maturação na carreira de magistério. A referida carreira prevê atuação de 25 anos de trabalho efetivo em escolas, conforme previsto na Lei n. 5.105, de 3 de maio de 2013 (DISTRITO FEDERAL, 2013), que reestrutura a carreira do magistério público no Distrito Federal.

O cruzamento da idade dos participantes com o tempo de trabalho na área de gestão escolar, permite concluir que, embora não apresentem muito tempo de experiência na função, possivelmente têm bagagem profissional de trabalhos anteriores, em escolas particulares ou trabalhos similares. Esse cenário favorece a realização de um trabalho efetivo na escola, pois 42,9\% dos gestores apresentam alguma experiência em gestão. Este fator, aliado à qualificação e à maturidade profissional, contribuem para o bom desempenho no cargo.

Sobre os fatores de motivação para o trabalho na escola, embora a função de diretor escolar seja gratificada, observou-se que a questão financeira tem peso irrelevante para o gestor aceitar a função na escola. Depreende-se que o compromisso com o trabalho desenvolvido é, de fato, o maior motivador, e 


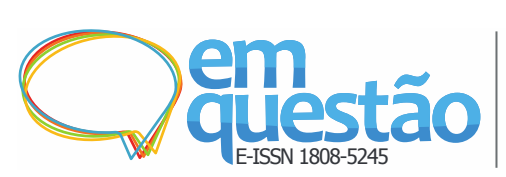

Tomada de decisão do gestor escolar das escolas públicas de ensino médio no Distrito Federal e a interface como letramento informacional

Patrícia Resende Pereira e Kelley Cristine Gonçalves Dias Gasque

reflete o que Gracindo (2012) propõe no estudo sobre as novas demandas para o gestor escolar, cuja prática deve estar consolidada em uma formação diferenciada, em estreita relação com a visão de educação e ensino em que acredita e defende. Desta forma, o gestor poderá atender novas exigências e viabilizar o compromisso de uma escola a serviço de uma sociedade mais justa e igualitária, com educação de qualidade para todos. O Quadro 01 apresenta a síntese do perfil sociodemográfico dos participantes da pesquisa, gestores das escolas públicas de ensino médio do DF.

Quadro 1 - Perfil dos participantes da pesquisa.

\begin{tabular}{|l|l|}
\hline Características do Gestor & Prevalência \\
\hline Idade & Entre 41 e 50 anos de idade \\
\hline Gênero & Feminino \\
\hline Formação acadêmica & Especialização \\
\hline Tempo de experiência em gestão escolar & De 01 a 05 anos \\
\hline Fatores de motivação para o trabalho & Gostar da profissão \\
\hline
\end{tabular}

Fonte: Elaborado pelas autoras.

Investigou-se de que forma os gestores buscam as informações, os fatores que mais influenciam na escolha, quais as maiores dificuldades e as fontes utilizadas para a busca de informação. Sabe-se que o processo de busca e uso da informação é complexo e dinâmico, e relaciona-se às necessidades, ao contexto e às condições do grupo que dela se utiliza.

Constatou-se que a informação disponibilizada na web domina a preferência na busca de informações para a tomada de decisões para 53\% dos respondentes. Formas clássicas de acesso à informação - como cartazes, quadros de aviso e murais - ainda são bastante utilizados. A opção de busca em "revistas, jornais, livros especializados" obteve a menor frequência.

Sobre as principais dificuldades para a tomada de decisão, os resultados mostraram que a maior delas é o volume excessivo de dados, além do prazo exíguo para se obter informações e problemas com os sistemas existentes, que, segundo os participantes, não fornecem as informações necessárias.

Os resultados encontrados ratificam a pesquisa de Braga (2016), que evidencia a intensificação do trabalho do gestor, das novas atribuições e da necessidade de gerenciar aspectos materiais e financeiros da escola, bem como articular parcerias em um cenário desafiador. Almeida (2015) aponta que, para 


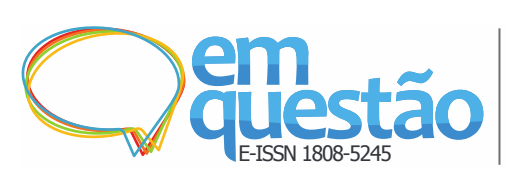

Tomada de decisão do gestor escolar das escolas públicas de ensino médio no Distrito Federal e a interface como letramento informacional

Patrícia Resende Pereira e Kelley Cristine Gonçalves Dias Gasque

$57,1 \%$ dos gestores escolares, a sobrecarga de trabalho e apoio insuficiente são alguns dos desafios. Infere-se que essa tendência se repete também nas escolas de ensino médio, tendo em vista a fala dos gestores entrevistados, que apontam novas responsabilidades para o gestor, o aumento de trabalho, a cobrança no retorno e resultados. Isso ocorre especialmente com a facilidade do acesso à informação por meios eletrônicos e aplicativos, como WhatsApp.

Os principais fatores intervenientes apontados por gestores na busca por conhecimento foram: a falta de interesse pelos cursos oferecidos, falta de tempo e dificuldade de acesso à divulgação em tempo hábil, conforme se observa no Quadro 2.

Quadro 2 - Síntese: formas de busca e uso da informação

\begin{tabular}{|c|c|}
\hline Questões & Predominância \\
\hline $\begin{array}{l}\text { Fonte utilizada com maior } \\
\text { frequência. }\end{array}$ & $\begin{array}{l}\text { Informações disponíveis no ambiente web, seja em } \\
\text { aplicativos, e-mail ou sites especializados. }\end{array}$ \\
\hline $\begin{array}{l}\text { Maior dificuldade para acesso às } \\
\text { informações e tomada de decisão. }\end{array}$ & $\begin{array}{l}\text { Volume excessivo de dados aliado à falta de tempo para se } \\
\text { obter informações. }\end{array}$ \\
\hline $\begin{array}{l}\text { Forma de arquivamento de } \\
\text { informações. }\end{array}$ & $95,2 \%$ dos gestores utilizam o computador da escola. \\
\hline $\begin{array}{l}\text { Frequência de participação/ } \\
\text { realização de reuniões e eventos. }\end{array}$ & $\begin{array}{l}71,4 \% \text { dos gestores realizam reuniões com toda a equipe } \\
\text { escolar mais de uma vez por semana e } 61,9 \% \text { realizam } \\
\text { com a própria equipe gestora. }\end{array}$ \\
\hline $\begin{array}{lr}\text { Aplicativo mais utilizado para } \\
\text { compartilhamento } \\
\text { informações. }\end{array}$ & WhatsApp \\
\hline $\begin{array}{l}\text { Participação em curso de } \\
\text { formação continuada. }\end{array}$ & $\begin{array}{l}\text { 90,5\% dos participantes estão com cursos em andamento } \\
\text { ou concluíram em 2016, voltados para a Formação para } \\
\text { gestores. }\end{array}$ \\
\hline $\begin{array}{l}\text { Fatores que interferem na busca } \\
\text { por conhecimento. }\end{array}$ & $\begin{array}{l}\text { Cursos oferecidos não despertam o interesse; } \\
\text { falta de tempo; } \\
\text { falta de acesso à divulgação dos cursos em tempo hábil. }\end{array}$ \\
\hline
\end{tabular}
Fonte: Elaborado pelas autoras.

Buscou-se, ainda, conhecer o comportamento, as atitudes, as dificuldades e as opiniões dos gestores quanto à avaliação e compreensão de informações, além das formas de compartilhamento. A avalanche de informações produzidas e veiculadas por meios diversos e a exigência de respostas em um tempo cada vez mais curto, resultam em sobrecarga extra para os gestores, que se sentem frustrados por não conseguirem absorver as informações e resolver o que precisam da maneira mais acertada. Esse fator, aliado ao acúmulo de tarefas, 
Tomada de decisão do gestor escolar das escolas públicas de ensino médio no Distrito Federal e a interface como letramento informacional

Patrícia Resende Pereira e Kelley Cristine Gonçalves Dias Gasque

transforma-se em estresse e desenvolve um novo tipo de mal, descrito por Wurman (1991, p.38) como "ansiedade de informação".

Um dado revelador da pesquisa é que 90,47\% dos participantes afirmam questionar a procedência das informações recebidas, e buscam confirmar a exatidão em outros documentos. Esse comportamento reflete a prática de gestão que Hartman (2015) defende como fator de sucesso no processo de ensino e aprendizagem, pois envolve a reflexão sobre a ação e a reflexão na ação, além de propor a avaliação crítica sobre o desempenho das próprias atividades. Podese inferir, ainda, que esse cuidado se deve ao fato de que os gestores precisam ser cautelosos ao informar, uma vez que o impacto na equipe de uma notícia falsa - ou não confirmada - pode ser desastroso, gerar desconfiança e causar desgastes desnecessários.

Quanto ao repasse das informações, a maioria dos gestores afirmaram que as informações recebidas das instâncias superiores são transmitidas com clareza até o destinatário final, dado que pode sinalizar a imparcialidade e o comprometimento com o trabalho desenvolvido. Todavia, percebe-se interferência na comunicação, pois alguns servidores criam polêmicas e intrigas ao compartilhar informação sobre questões políticas nos grupos de mensagens, sem verificar a autenticidade. Outros utilizam indevidamente as ferramentas, cometem deslizes e precisam ser orientados. Esse aspecto também pode ser observado no cotidiano da Secretaria de Educação, pois desde a implantação do Sistema Eletrônico de Informações (SEI) ${ }^{2}$, em 2017, percebe-se que vários servidores ainda não têm domínio da ferramenta, apesar da formação inicial para utilizar o sistema. Algumas vezes, os erros comprometem o andamento dos processos.

O estudo investigou, ainda, a relação entre o processo de tomada de decisão e a interface com os padrões de letramento informacional. Verificou-se como são realizadas as práticas no cotidiano, quais as maiores demandas para a direção e como ocorre a comunicação entre a equipe gestora e demais setores da escola. Os resultados da pesquisa apontam a necessidade de acompanhamento e avaliação das atividades previstas no Projeto Político-Pedagógico (PPP) como a atividade mais frequente no dia a dia, seguida das decisões relacionadas a conflitos no ambiente escolar. Em função dessas demandas, outras atividades de 


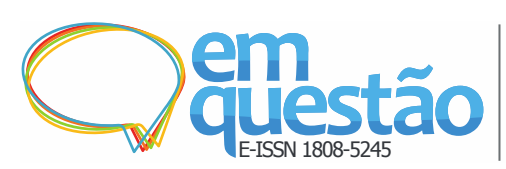

Tomada de decisão do gestor escolar das escolas públicas de ensino médio no Distrito Federal e a interface como letramento informacional

Patrícia Resende Pereira e Kelley Cristine Gonçalves Dias Gasque

importância pedagógica ficam praticamente sem condições de tempo para discussão e implementação com a equipe, como o acompanhamento de atividades pedagógicas junto aos professores, a supervisão do avanço escolar dos estudantes e propostas de intervenção para melhoria do rendimento, por exemplo.

Os participantes da pesquisa concordam que as informações disponibilizadas pela Secretaria da Educação - como e-mails, memorandos, circulares, ofícios e pareceres - favorecem a tomada de decisão. Afirmam, ainda, a importância de verificar a origem das informações e de confrontá-las com outros documentos, de forma a evitar o repasse de dados equivocados para a equipe. Outras informações utilizadas pelos gestores são os indicadores de desempenho, aproveitamento de sugestões dos colegas e tomada de decisões compartilhada com a equipe. O quadro a seguir sintetiza esses resultados.

Quadro 3 - Processo de tomada de decisão (síntese)

\begin{tabular}{|c|c|}
\hline Atividades mais frequentes & Predominância \\
\hline $\begin{array}{l}\text { Consultam informações disponíveis para tomada de } \\
\text { decisões. }\end{array}$ & $\begin{array}{l}19 \text { gestores responderam que concordam } \\
\text { total e/ou parcialmente realizar esta } \\
\text { atividade, o que corresponde a } 90 \% \text { dos } \\
\text { participantes. }\end{array}$ \\
\hline $\begin{array}{l}\text { Realizam com frequência o acompanhamento e } \\
\text { avaliação das atividades previstas no Projeto } \\
\text { Político- Pedagógico (PPP). }\end{array}$ & $\begin{array}{l}10 \text { respondentes, num total de } 12 \\
\text { participantes. }\end{array}$ \\
\hline Consultam o PPP para tomar decisões. & $\begin{array}{l}16 \text { participantes - em concordância total } \\
\text { e/ou parcial. }\end{array}$ \\
\hline Verificam a origem das informações. & $\begin{array}{l}18 \text { participantes - em concordância total } \\
\text { e/ou parcial. }\end{array}$ \\
\hline $\begin{array}{l}\text { Decisões relacionadas a conflitos no ambiente } \\
\text { escolar. }\end{array}$ & $\begin{array}{l}\text { É a } 2^{\text {a }} \text { ocorrência mais listada, com quase } \\
80 \% \text { de frequência no dia a dia do gestor } \\
\text { escolar. }\end{array}$ \\
\hline Resolução de problemas de pessoal. & $\begin{array}{l}\text { Atividade que ocupa o } 3^{\circ} \text { lugar na } \\
\text { frequência das tarefas cotidianas do gestor } \\
\text { escolar. }\end{array}$ \\
\hline $\begin{array}{l}\text { Consideram sugestões recebidas, tomam decisões } \\
\text { com a participação da equipe, consultam } \\
\text { indicadores de desempenho e resultados alcançados } \\
\text { pela escola para melhoria do trabalho desenvolvido. }\end{array}$ & $\begin{array}{l}12 \text { dos gestores participantes } \\
\text { concordância total. }\end{array}$ \\
\hline
\end{tabular}

Fonte: Elaborado pelas autoras.

O gerenciamento e uso da informação para o desenvolvimento das atividades da direção escolar mais destacadas foram: dificuldades de acesso, armazenamento, recuperação, compartilhamento, busca e uso da informação para tomada de decisão. Quanto aos tipos de informação necessários para a 


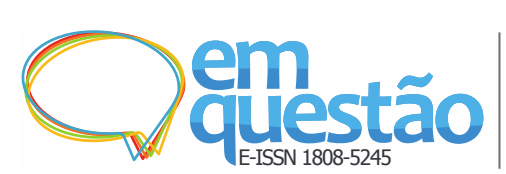

Tomada de decisão do gestor escolar das escolas públicas de ensino médio no Distrito Federal e a interface como letramento informacional

Patrícia Resende Pereira e Kelley Cristine Gonçalves Dias Gasque

tomada de decisão, os gestores responderam que utilizam as disponíveis na internet, especialmente dos sistemas: SEI, SICOP $^{3}$ e I-educar ${ }^{4}$. Outras fontes são os documentos oficiais, como o Regimento Escolar e o PPP da escola.

As demandas chegam nas escolas por meios diversos, como e-mail, SEI, WhatsApp, e são distribuídas internamente para cada responsável, de acordo com a natureza: pedagógica, administrativa ou financeira. Por sua vez, os gestores buscam informações em documentos oficiais e com outros colegas para resolverem as demandas. Se necessário e possível, a equipe gestora reúne-se para decidir, seja por meio presencial ou virtual, principalmente por meio do aplicativo WhatsApp.

Quanto aos fatores que mais influenciam a escolha dos gestores por determinadas fontes de informação para tomada de decisão, descobriu-se que o principal critério é observar a origem da informação. Para se resguardarem, os gestores amparam-se em documentos oficiais e legislação da área.

Os resultados encontrados indicam que o compartilhamento de informação pelos gestores ocorre de forma autônoma e responsável, em que se faz uso das normas, propiciando o desenvolvimento da aprendizagem independente e cuidado ético com as informações, tanto no recebimento quanto ao fazer o compartilhamento das mesmas. Em conjunto, os resultados obtidos contribuíram para melhor compreender a inter-relação entre os conceitos de tomada de decisão e a intersecção com os padrões de letramento informacional. O Quadro 4 apresenta articulação entre os padrões de letramento, de acordo com o modelo proposto pela International Federation of Library Associations and Institutions (IFLA) e descrito por Lau (2007), e apresenta indicadores de competência a partir dos dados coletados com os gestores participantes da pesquisa. 
Tomada de decisão do gestor escolar das escolas públicas de ensino médio no Distrito Federal e a interface como letramento informacional

Patrícia Resende Pereira e Kelley Cristine Gonçalves Dias Gasque

Quadro 4 - Padrões de letramento informacional e abordagens sobre tomada de decisão

\begin{tabular}{|c|c|c|}
\hline $\begin{array}{c}\text { Padrões de } \\
\text { Letramento } \\
\text { Informacional }\end{array}$ & Indicadores & $\begin{array}{c}\text { Atitudes dos gestores } \\
\text { escolares }\end{array}$ \\
\hline $\begin{array}{l}\text { a) ACESSO. } \\
\text { Define como o } \\
\text { indivíduo acessa a } \\
\text { informação, de } \\
\text { forma eficaz e } \\
\text { eficiente. }\end{array}$ & $\begin{array}{l}\text { 1. Definição e articulação da necessidade } \\
\text { de informação. O usuário... } \\
\text { a) Define ou reconhece a necessidade de } \\
\text { informação. } \\
\text { b) Decide fazer algo para encontrar a } \\
\text { informação. } \\
\text { c) Expressa e define a necessidade de } \\
\text { informação. Inicia o processo de } \\
\text { busca. } \\
\text { 2. Localização da informação. } \\
\text { usuário... } \\
\text { a) Identifica e avalia as fontes potenciais } \\
\text { de informação. } \\
\text { b) Desenvolve estratégias de busca. } \\
\text { c) Acessa fontes de informação } \\
\text { selecionadas. } \\
\text { deleciona e recupera a informação. }\end{array}$ & $\begin{array}{l}\text { Os gestores, normalmente, } \\
\text { não definem a melhor fonte } \\
\text { de informação, conforme a } \\
\text { necessidade, nem } \\
\text { selecionam previamente } \\
\text { um método de busca, } \\
\text { agindo de forma mecânica } \\
\text { e intuitiva. O surgimento de } \\
\text { demandas para resolução } \\
\text { de problemas leva a } \\
\text { procurar informações em } \\
\text { mais de uma fonte: } \\
\text { legislação em vigor, } \\
\text { documentos oficiais, PPP } \\
\text { das escolas, e-mails e } \\
\text { internet. } \\
\text { De maneira geral, os } \\
\text { gestores procuram os } \\
\text { canais mais acessíveis. O } \\
\text { padrão da pesquisa se inicia } \\
\text { no SEI e pode-se ampliar a } \\
\text { busca na internet ou em } \\
\text { documentos oficiais como } \\
\text { o regimento escolar, o PPP } \\
\text { e legislação, por exemplo. } \\
\text { Eles não estabelecem } \\
\text { estratégias de busca } \\
\text { antecipadamente e alguns } \\
\text { revelaram ter dificuldades } \\
\text { para fazer uso do sistema } \\
\text { SEI. }\end{array}$ \\
\hline $\begin{array}{c}\text { Padrões de } \\
\text { Letramento } \\
\text { Informacional }\end{array}$ & Indicadores & $\begin{array}{c}\text { Atitudes dos gestores } \\
\text { escolares }\end{array}$ \\
\hline $\begin{array}{l}\text { b) AVALIAÇÃO. } \\
\text { O usuário avalia a } \\
\text { informação de } \\
\text { maneira crítica e } \\
\text { competente. }\end{array}$ & $\begin{array}{l}1 \text { - Avaliação da informação. O } \\
\text { usuário... } \\
\text { a) Analisa, examina e extrai a } \\
\text { informação. } \\
\text { b) Generaliza e interpreta a informação. } \\
\text { c) Seleciona e sintetiza a informação. } \\
\text { d) Avalia a exatidão e relevância da } \\
\text { informação recuperada. }\end{array}$ & $\begin{array}{l}\text { O gestor examina a } \\
\text { informação e a interpreta, } \\
\text { consultando outros colegas } \\
\text { da equipe ou de instâncias } \\
\text { superiores, como a } \\
\text { Regional de Ensino ou a } \\
\text { Sede da Secretaria. Ao se } \\
\text { confrontar com alguma } \\
\text { nova experiência ou } \\
\text { conhecimento, tendem a } \\
\text { retrair-se, a menos que } \\
\text { sejam informados } \\
\text { compreendam } \\
\text { importância da mudança } \\
\text { antecipadamente. }\end{array}$ \\
\hline
\end{tabular}


Tomada de decisão do gestor escolar das escolas públicas de ensino médio no Distrito Federal e a interface como letramento informacional

Patrícia Resende Pereira e Kelley Cristine Gonçalves Dias Gasque

\begin{tabular}{|c|c|c|}
\hline & $\begin{array}{l}2 \text { - Organização da informação. O } \\
\text { usuário... } \\
\text { a) Ordena e categoriza a informação. } \\
\text { b) Reúne e organiza a informação } \\
\text { recuperada. } \\
\text { c) Determina qual a melhor e de maior } \\
\text { utilidade. }\end{array}$ & $\begin{array}{l}\text { Embora façam uso de } \\
\text { ferramentas tecnológicas, e } \\
\text { afirmem arquivar as } \\
\text { informações, muitas vezes } \\
\text { os gestores não conseguem } \\
\text { localizar nem recuperar, de } \\
\text { forma eficaz, informações } \\
\text { importantes para o } \\
\text { trabalho. Buscam a } \\
\text { informação, mas não } \\
\text { conseguem avaliar a } \\
\text { importância dela para } \\
\text { solucionar o problema. } \\
\text { Logo, consultam a } \\
\text { Regional de Ensino ou a } \\
\text { Secretaria em busca de } \\
\text { orientações. }\end{array}$ \\
\hline $\begin{array}{c}\text { Padrões de } \\
\text { Letramento } \\
\text { Informacional }\end{array}$ & Indicadores & $\begin{array}{c}\text { Atitudes dos gestores } \\
\text { escolares }\end{array}$ \\
\hline \multirow[b]{2}{*}{$\begin{array}{c}\text { c) USO. } \\
\text { O usuário aplica a } \\
\text { informação de } \\
\text { maneira precisa e } \\
\text { criativa. }\end{array}$} & $\begin{array}{l}\text { 1 - Uso da informação. O usuário... } \\
\text { a) Busca novas formas de comunicar, } \\
\text { apresentar e usar a informação. } \\
\text { b) Aplica a informação recuperada. } \\
\text { c) Apreende ou internaliza a } \\
\text { informação como conhecimento } \\
\text { pessoal. } \\
\text { d) Apresenta o produto da informação. }\end{array}$ & $\begin{array}{l}\text { Os gestores tratam as } \\
\text { informações antes de } \\
\text { comunicá-las à equipe, seja } \\
\text { por meio de reuniões, } e \text { - } \\
\text { mails ou apresentação de } \\
\text { algum novo projeto. Fazem } \\
\text { uso das mesmas para } \\
\text { tomada de decisão em } \\
\text { questões administrativas e } \\
\text { pedagógicas. Contudo, não } \\
\text { foi possível verificar a } \\
\text { aplicação no } \\
\text { desenvolvimento pessoal, } \\
\text { por não ser objeto deste } \\
\text { estudo. }\end{array}$ \\
\hline & $\begin{array}{l}\text { 2- Comunicação e uso ético da } \\
\text { informação. O usuário... } \\
\text { a) Compreende o uso ético da } \\
\text { informação. } \\
\text { b) Respeita o uso legal da informação. } \\
\text { c) Comunica o produto da informação } \\
\text { com reconhecimento da propriedade } \\
\text { intelectual. } \\
\text { d) Usa os padrões para o } \\
\text { reconhecimento da informação. }\end{array}$ & $\begin{array}{l}\text { Observou-se cuidado } \\
\text { constante quanto ao } \\
\text { compartilhamento de } \\
\text { informações, de forma ética } \\
\text { e responsável, preservando } \\
\text { a confiabilidade dos dados } \\
\text { repassados, a } \\
\text { procedência/autoria e } \\
\text { evitando distorções que } \\
\text { possam causar problemas } \\
\text { para o desenvolvimento do } \\
\text { trabalho. }\end{array}$ \\
\hline
\end{tabular}

Fonte: Adaptado dos padrões de LI propostos por Catts e Lau (2007). 
Tomada de decisão do gestor escolar das escolas públicas de ensino médio no Distrito Federal e a interface como letramento informacional Patrícia Resende Pereira e Kelley Cristine Gonçalves Dias Gasque

Os resultados dos dados coletados dos gestores educacionais em relação aos padrões do letramento informacional mostram a ausência de planejamento dos gestores para identificar a informação necessária e as melhores fontes para buscá-la. Confirma-se a proposição observada em vários estudos: os gestores buscam os canais mais acessíveis, às vezes, em detrimento da qualidade de informações. Isso pode ser observado, por exemplo, na pesquisa de Austin et al. (2012). De acordo com Shah e Oppenheimer (2008), em uma grande revisão sobre tomada de decisão, uma das estratégias heurísticas mais usada envolve o uso de informação de fácil acesso. Estratégias heurísticas são atalhos que os humanos usam para tomar decisão.

Ao buscar ou receber alguma informação, os gestores consultam colegas da equipe ou de instâncias superiores. Isso demonstra preocupação com a realização correta das atividades, mas também pode evidenciar insegurança ou problema na formação dos gestores. Muitas vezes, esses profissionais são eleitos para o cargo, mas não possuem formação sistemática e adequada. Em pesquisa recente sobre formação de líderes de projetos, Jalal e Jergeas (2015) relatam haver lacuna entre o que se oferece em termos de formação e o que é necessário para se lidar em um complexo e dinâmico ambiente de trabalho. Nesse sentido, recomendam que a formação deve privilegiar: (1) desenvolvimento do pensamento crítico para lidar com a complexidade; (2) desenvolvimento de parâmetros mais fáceis de gerenciamento de projetos, especialmente habilidades interpessoais e liderança, em vez de habilidades técnicas; e (3) preparação de profissionais engajados no contexto de projetos da vida real.

Outro fator é que os gestores não organizam ou arquivam adequadamente as informações decorrentes das atividades cotidianas. Portanto, podem haver lacunas na recuperação de informação, o que, por sua vez, pode impactar na tomada de decisão. Teevan, Jones e Bederson (2006) explicam sobre a importância do gerenciamento de informações pessoais, argumentando que a organização da informação possibilita perder menos tempo com as atividades onerosas e propensas a erros de gerenciar informações, deixando mais tempo livre para fazer uso criativo e inteligente das informações.

Em relação ao uso da informação, há preocupação dos gestores em verificar a procedência da informação e entendê-la antes de repassá-la à 


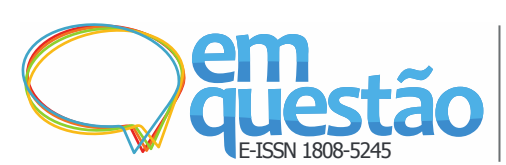

Tomada de decisão do gestor escolar das escolas públicas de ensino médio no Distrito Federal e a interface como letramento informacional

Patrícia Resende Pereira e Kelley Cristine Gonçalves Dias Gasque

comunidade educacional. $\mathrm{O}$ grande aumento do compartilhamento de informações falsas (fake News) pode criar tumultos e gerar imprecisão na compreensão da informação. Sobre isso, Gasque e Fialho (2018) argumentam que

[...] a implementação de programas de letramento informacional é fundamental para a formação de pessoas com autonomia para lidar com a informação, essencial na sociedade da aprendizagem, em que os pilares de desenvolvimento centram-se na grande produção de informação, no uso intensivo das tecnologias de comunicação e informação e no processo de aprendizagem permanente.(GASQUE; FIALHO, 2018, p. 11).

Em suma, conclui-se que os gestores apresentam algumas competências informacionais aprendidas de forma mecânica, tentativa e erro, e pelas próprias experiências. Observa-se que a busca da informação é restrita aos sistemas e pessoas conhecidas. Mais ainda, a formação dos gestores não abrange, de forma sistemática e aprofundada, os conhecimentos e competências para lidar com a informação de forma eficaz e eficiente. Evidentemente, isso pode comprometer o desempenho das atividades desses gestores.

\section{Considerações finais}

O foco da pesquisa foi a análise do comportamento de busca e uso da informação para tomada de decisão do gestor escolar, considerando os padrões de letramento informacional. Os resultados mostram que o principal acesso à informação é realizado pela internet e que o volume de dados aliado à falta de tempo para obtenção de informações dificulta a tomada de decisão. Para tomar decisões, os gestores consultam informações disponíveis na escola, além do Projeto Político-Pedagógico. Verificam a origem da informação recebida e os resultados alcançados pela escola nas avaliações do governo. Os resultados permitiram consolidar a articulação entre os padrões de letramento e apresentar indicadores de competência no processo decisório dos gestores escolares.

Destaca-se a mudança no comportamento quanto à busca e ao uso das informações para tomada de decisões, marcada por dois aspectos. De um lado, que, atualmente, o acesso à internet tem sido cada vez mais facilitado pelo uso de novas tecnologias e redes on-line. Por outro, o volume de dados, o excesso de 


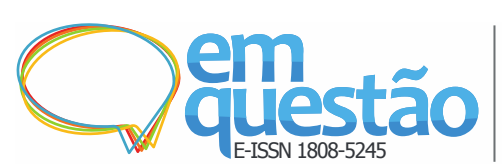

Tomada de decisão do gestor escolar das escolas públicas de ensino médio no Distrito Federal e a interface como letramento informacional

Patrícia Resende Pereira e Kelley Cristine Gonçalves Dias Gasque

demandas e a exigência de respostas imediatas comprometem a qualidade do trabalho e do processo decisório dos gestores escolares.

Tanto na revisão de literatura quanto nos depoimentos das entrevistas e respostas dos questionários, constatou-se a incorporação da tecnologia como ferramenta indispensável no cotidiano gerencial. Nesse contexto, revelou-se o uso intenso de aplicativos para disseminação da informação e gestão de processos, como o Sistema Eletrônico de Informações (SEI), implantado em 2017 na Secretaria de Estado de Educação do Distrito Federal.

Os dados coletados no estudo corroboraram ainda com os índices apontados nos indicadores oficiais, ao destacarem a importância da formação dos profissionais para o desenvolvimento das atividades educacionais e disseminação do conhecimento. No que se refere ao contexto do letramento informacional, evidenciou-se a necessidade da criação de uma política clara quanto aos processos de formação daqueles que atuam na gestão escolar. Nesse sentido, sugere-se a adoção de práticas do processo de letramento informacional - considerando os pressupostos do pensamento reflexivo - para desenvolver novas competências nos gestores escolares e, dessa forma, favorecer o sucesso do processo ensino-aprendizagem.

\section{Referências}

ALMEIDA, Maruska Pereira de. O uso da informação educacional na perspectiva dos gestores escolares de estabelecimentos de anos iniciais do ensino fundamental da rede pública do Distrito Federal. 2015. Dissertação (Mestrado em Ciência da Informação) - Universidade de Brasília, Brasília, 2015.

ALVES, Ana Paula Meneses. Competência Informacional e o uso ético da informação na produção científica: o papel do bibliotecário na produção intelectual no ambiente acadêmico. 2016. Tese (Doutorado em Ciência da Informação) - Universidade Estadual Paulista, São Paulo, 2016.

AUSTIN, Erica Weintraub et al. The relationships of information efficacy and Media literacy skills to knowledge and self-efficacy for health-related decision making. Journal of American College Health, Boston, v. 60, n. 8, p. 548-554, 2012.

BLAKENEY, Allison Black. Connecting Best Practices: an examination of Public School Principals' Knowledge and Perceptions of Their School Library 
Tomada de decisão do gestor escolar das escolas públicas de ensino médio no Distrito Federal e a interface como letramento informacional Patrícia Resende Pereira e Kelley Cristine Gonçalves Dias Gasque

Media Programs. 2014. Dissertation (Doctoral Dissertation) - Alabama State University, Alabama, 2014.

BOTHA, Joalise. Beliefs and attitudes of school management about the implementation of Information and Communication Technology in schools. 2013. Tesis (Doctorate). University of Pretoria, South Africa, 2013.

BRAGA, Luiz Ricardo Pereira de Almeida. A intensificação do trabalho do diretor escolar. 2016. Dissertação (Mestrado em Educação) - Programa de PósGraduação em Educação, Universidade de Brasília, Brasília, 2016.

BRASIL. Ministério da Educação. Lei n ${ }^{\circ}$ 9.394/1996, de 20 de dezembro de 1996. Estabelece as diretrizes e bases da educação nacional. Diário Oficial [da] União, Brasília, 23 dez. 1996.

CATTS, Ralph; LAU, Jesús. Hacia unos indicadores de Alfabetización Informacional: marco conceptual elaborado por Ralph Catts y Jesús Lau. Madrid: Ministerio de Cultura, 2009.

CHOO, C. Wei; ROCHA, Eliana. A organização do conhecimento: como as organizações usam a informação para criar conhecimento, construir conhecimento e tomar decisões. São Paulo: Senac, 2003.

CRESWELL, John W. Projeto de pesquisa: métodos qualitativo, quantitativo e misto. Porto Alegre: Artmed, 2010.

DISTRITO FEDERAL. Lei ${ }^{\circ}$ 5.105, de 3 de maio de 2013. Reestrutura a carreira do magistério público no Distrito Federal. Diário Oficial do Distrito Federal, Brasília, 3 maio 2013.

GADOTTI, Moacir. Gestão democrática da educação com participação popular no planejamento e na organização da educação nacional. [S.l.]: CONAE, 2014.

GASQUE, Kelley Cristine Gonçalves Dias; FIALHO, Janaina. Fake News. Correio Braziliense, Brasília, n. 20069, 2 maio 2018. Opinião, p. 11.

GASQUE, Kelley Cristine Gonçalves Dias. Arcabouço conceitual do letramento informacional. Ciência da Informação, Brasília, v. 39, n. 3, p. 83-92, 2010.

GASQUE, Kelley Cristine Gonçalves Dias. Comportamento dos professores da educação básica na busca de informação para a formação continuada: estudo de caso dos Colégios Maristas. 2003. Dissertação (Mestrado em Ciência da Informação) - Universidade de Brasília, Brasília, 2003.

GASQUE, Kelley Cristine Gonçalves Dias. O pensamento reflexivo na busca e no uso da informação na comunicação científica. 2008. Tese (Doutorado em Ciência da Informação) - Universidade de Brasília, Brasília, 2008. 


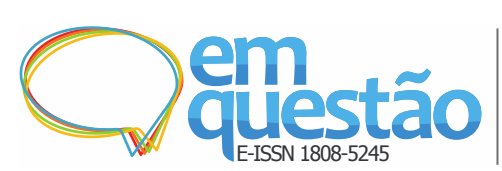

Tomada de decisão do gestor escolar das escolas públicas de ensino médio no Distrito Federal e a interface como letramento informacional Patrícia Resende Pereira e Kelley Cristine Gonçalves Dias Gasque

GASQUE, Kelley Cristine G. D.; CUNHA, Marcus Vinícius da. A epistemologia de John Dewey e o letramento informacional. TransInformação, Campinas, v. 22, n. 2, p. 139-146, 2010.

GASQUE, Kelley Cristine Gonçalves Dias. Letramento informacional: pesquisa, reflexão e aprendizagem. Brasília: UnB, 2012.

GRACINDO, Regina Vinhaes. O gestor escolar e as demandas da gestão democrática: exigências, práticas, perfil e formação. Retratos da Escola, Brasília, v. 3, n. 4, p. 1-13, 2012.

HARTMAN, Hope J. Como ser um professor reflexivo em todas as áreas do conhecimento. Porto Alegre: AMGH, 2015.

JALAL, Ramazani; JERGEAS, George. Project managers and the journey from good to great: The benefits of investment in project management training and education. International Journal of Project Management, Alberta, v. 33, n. 1, p.41-52, 2015.

KAHNEMAN, Daniel. Rápido e devagar: duas formas de pensar. Rio de Janeiro: Objetiva, 2012.

KHANNA, Poonam; JONES, Carla D.; BOIVIE, Steven. Director Human Capital, Information Processing Demands, and Board Effectiveness. Journal of Management, Los Angeles, v. 40, n. 2, p. 557-585, 2014.

LAU, Jesús. Diretrizes sobre desenvolvimento de habilidades em informação para a aprendizagem permanente. Boca del Rio: IFLA, 2007.

LÜCK, Heloísa. Liderança em gestão escolar. Petrópolis: Vozes, 2008.

MANABE, Sérgio Hiroshi; KAIMEN, Maria Júlia Giannasi. Competência informacional na Auditoria Interna da Universidade Estadual de Londrina. Informação@Profissões, Londrina, v. 1, n. 1/2, p. 77-92, 2013.

MORESI, Eduardo Amadeu Dutra. Delineando o valor do sistema de informação de uma organização. Ciência da Informação, Brasília, v. 29, n. 1, p. 14-24, 2000.

OTTONICAR, Selma Letícia Capinzaiki. Análise teórico-descritiva da competência em informação de gestores como fator de competitividade das indústrias de eletroeletrônicos da cidade de Garça/SP. 2016. Dissertação (Mestrado em Ciência da Informação) - Faculdade de Filosofia e Ciências, Universidade Estadual Paulista, São Paulo, 2016.

SANTOS, Vanessa Cristina Bissoli dos. Competência em informação na construção da inteligência competitiva nas organizações: o caso da empresa 


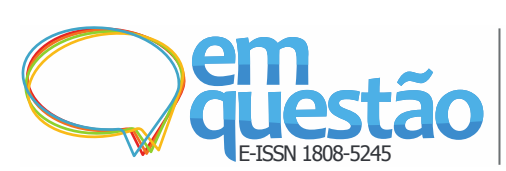

Tomada de decisão do gestor escolar das escolas públicas de ensino médio no Distrito Federal e a interface como letramento informacional Patrícia Resende Pereira e Kelley Cristine Gonçalves Dias Gasque

Mizumo. Dissertação (Mestrado em Ciência da Informação) - Faculdade de Filosofia e Ciências, Universidade Estadual Paulista, São Paulo, 2014.

SHAH, Anuj K.; OPPENHEIMER, Daniel M. Heuristics made easy: an effortreduction framework. Psychological Bulletin, Washington, v. 134, n. 2, p. $207-$ 222, 2008.

TEEVAN, Jaime; JONES, William; BEDERSON, Benjamin B. Personal Information Management. Communications of the ACM, Nova York, v. 49, n. 1, p. 40-44, 2006

WURMAN, Richard Saul. Ansiedade de informação. São Paulo: Cultura Editores Associados, 1991.

XAVIER, Antonio Carlos da R. A gestão da qualidade e excelência dos serviços educacionais: custos e benefícios de sua implementação. Rio de Janeiro: IPEA, 1996.

YAFUSHI, Cristiana Aparecida Portero. A Competência em informação para a construção de conhecimento no processo decisório: estudo de caso na Duratex de Agudos (SP). 2015. Dissertação (Mestrado em Ciência da Informação) - Faculdade de Filosofia e Ciências, Universidade Estadual Paulista Júlio de Mesquita Filho, São Paulo, 2015.

YIN, Robert K. Estudo de caso: planejamento e métodos. Porto Alegre:

Bookman, 2005.

\title{
The decision making process of school managers in the Federal District public high schools and its interface with information literacy
}

\begin{abstract}
This study analyzed the behavior in search and use of information for decision making of school managers in relation to the information literacy patterns in the high schools of the Distrito Federal, that are part of the public school system. The research is qualitative-quantitative, based on official documents of the educational system of the Distrito Federal, a questionnaire and a semi-structured interview. The results show that the main access to information is carried out through the internet and also that the volume of data along with the lack of time to obtain information hinders the decision making. In order to make decisions, besides the political pedagogical projects, managers consult information available at schools. They verify the origin of the information received and the results achieved by the school in external evaluations, which are proposed by the government. Finally, the data collected from school managers in relation to information literacy patterns show the
\end{abstract}




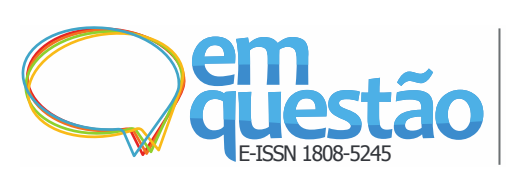

Tomada de decisão do gestor escolar das escolas públicas de ensino médio no Distrito Federal e a interface como letramento informacional

Patrícia Resende Pereira e Kelley Cristine Gonçalves Dias Gasque

development of few skills and the need for systematic and adequate training to learn how to deal with information.

Keywords: Information Literacy. School management. Decision making. High school.

Recebido: $22 / 05 / 2018$

Aceito: $22 / 11 / 2018$

1 Essa base de dados contempla artigos publicados em periódicos científicos do Brasil e de Portugal.

A BDTD é uma iniciativa do Instituto Brasileiro de Informação em Ciência e Tecnologia (IBICT), com o objetivo de integrar os sistemas de informação de teses e dissertações existentes no país.

A Proquest é uma plataforma com base de dados, contendo artigos de periódicos, dissertações, teses e outros.

Online Computer Library Center, Inc., também conhecida como OCLC, é uma organização sem fins lucrativos considerada a maior cooperativa de bibliotecas, museus e arquivos do mundo.

LISTA é a base de dados bibliográfica mais antiga no campo da ciência da informação.

ERIC: base de dados bibliográfica da área de Educação, desenvolvida pelo Instituto de Ciência da Educação (IES) do Departamento de Educação dos Estados Unidos.

O Repositório Institucional da UnB é coordenado pela Biblioteca Central e realiza a gestão e disseminação da produção científica e acadêmica da Universidade de Brasília.

2 O Sistema Eletrônico de Informações (SEI) é um software do governo, que possibilita a gestão de processos e documentos eletrônicos, com o objetivo de reduzir o papel como suporte físico para documentos institucionais e o compartilhamento do conhecimento com atualização e comunicação de novos eventos em tempo real.

3 SICOP é um sistema informatizado que permite ao servidor público verificar a movimentação de processos nos órgãos do governo de Brasília.

4 I-educar é software utilizado para gerenciar informações escolares na rede pública de ensino. 